University of Louisville

ThinkIR: The University of Louisville's Institutional Repository

Faculty Scholarship

8-3-2017

\title{
Modulation of cellular energetics by galactose and pioglitazone.
}

\author{
David Grimm \\ Eastern Illinois University \\ Leonardo Altamirano \\ Eastern Illinois University \\ Sudip Paudel \\ Eastern Illinois University \\ Leah Welker \\ Eastern Illinois University \\ Mary E. Konkle \\ Eastern Illinois University \\ See next page for additional authors
}

Follow this and additional works at: https://ir.library.louisville.edu/faculty

Part of the Biology Commons, and the Cell and Developmental Biology Commons

\section{Original Publication Information}

This is the accepted manuscript of the following article:

Grimm, D., Altamirano, L., Paudel, S. et al. "Modulation of Cellular Energetics by Galactose and Pioglitazone." 2017. Cell and Tissue Research: 6 pp.

The final publication is available at Springer via http://doi.org/10.1007/s00441-017-2657-1

This Article is brought to you for free and open access by ThinkIR: The University of Louisville's Institutional Repository. It has been accepted for inclusion in Faculty Scholarship by an authorized administrator of ThinkIR: The University of Louisville's Institutional Repository. For more information, please contact thinkir@louisville.edu. 


\section{Authors}

David Grimm, Leonardo Altamirano, Sudip Paudel, Leah Welker, Mary E. Konkle, Nilay Chakraborty, and Michael A. Menze 


\section{Modulation of Cellular Energetics by Galactose and Pioglitazone}

David Grimm ${ }^{1}$, Leonardo Altamirano ${ }^{1}$, Sudip Paudel ${ }^{1}$, Leah Welker ${ }^{1}$, Mary E. Konkle ${ }^{2}$, Nilay Chakraborty $^{3}$, and Michael A. Menze ${ }^{4 *}$

${ }^{1}$ Department of Biological Sciences, Eastern Illinois University, Charleston, IL 61920

${ }^{2}$ Department of Chemistry, Eastern Illinois University, Charleston, IL 61920

${ }^{3}$ Department of Mechanical Engineering, University of Michigan Dearborn, Dearborn, MI 48128

${ }^{4}$ Department of Biology, University of Louisville, Louisville, KY, 40292

*Address for correspondence: Michael A. Menze, Tel: 502-852-8962, email:

Michael.menze@louisville.edu 


\begin{abstract}
The Warburg effect is ameliorated by culturing transformed cells in the presence of galactose instead of glucose as the primary carbon source. However, metabolic consequences that are in addition to sensitizing the cells to mitochondrial toxins may occur. As such, the screening of pharmaceutical agents against transformed cells while using galactose must be carefully evaluated. Pioglitazone is used in clinical applications to treat type-2 diabetes, but clearly has other off target effects. Human hepatocellular carcinoma cells (HepG2) were cultured in glucose or galactosecontaining medium to investigate the role of pioglitazone on cellular bioenergetics employing calorimetry and respirometry. Compared to cells cultured in $10 \mathrm{mM}$ glucose, HepG2 cells cultured in the presence of $10 \mathrm{mM}$ galactose showed decreased metabolic activity as measured by cellular heat flow. Interestingly, cellular heat flow increased after addition of pioglitazone for cells cultured in glucose, but not for cells cultured in galactose. Our calorimetric data indicate that a reduction in cellular capacity for glycolysis might be the mechanism responsible for the increase in sensitivity to pioglitazone, and likely mitochondrial toxins in general, for cells cultured in galactose. Furthermore, oxygen consumption rates were decreased after addition of pioglitazone to cells grown in glucose, but remained unchanged for cells grown in presence of galactose. Taken together, we demonstrate that pioglitazone induced a reduction in mitochondrial activity that was partially compensated via an increase in glycolysis in the presence of glucose.
\end{abstract}

Keywords: Metabolic poise, oxidative phosphorylation, respiration, calorimetry, Warburg effect 


\section{Introduction}

Thiazolidinediones (TZD) are effective insulin sensitizers used to treat type-2 diabetes, and these compounds have been shown to reduce the risk of conversion from impaired glucose tolerance to type-2 diabetes (Day 1999; DeFronzo et al. 2011). Most of the antidiabetic properties of TZDs are believed to be mediated through changes in gene expression patterns after binding to the nuclear peroxisome proliferator-activated receptor (PPAR)- $\gamma$ (Cariou et al. 2012). However, mounting evidence indicates that at least part of TZD action is independent of PPAR- $\gamma$-mediated transactivation and transrepression of target genes (Feinstein et al. 2005). Pleiotropic mechanisms in addition to PPAR- $\gamma$ binding appear to be crucial for the broad pharmacological profile of TZDs and potentially include several effects on mitochondria, including inhibition of the respiratory complex I (Brunmair et al. 2004), inhibition of the mitochondrial pyruvate carrier (Divakaruni et al. 2013), and binding to CISD1 (Colca et al. 2004; Geldenhuys et al. 2014; Paddock et al. 2007).

First described nearly 60 years ago by Otto Warburg, highly proliferating cancer cells are often characterized by a shift in energy production from oxidative phosphorylation to glycolysis despite the presence of saturating concentrations of oxygen ('aerobic glycolysis') (Kim et al. 2006; Vander Heiden et al. 2009; Warburg 1956). In some cases, mitochondrial respiration rates can be rescued if glucose levels are low, and suppression in respiration by high glucose concentration is a phenomenon known as the Crabtree effect (Diaz-Ruiz et al. 2011; Ibsen 1961). For example, substitution of the primary energy substrate glucose by galactose increases mitochondrial activity in several models including adenocarcinoma (HeLa) and hepatocellular carcinoma (HepG2) cells, and sensitizes HepG2 cells to some mitochondrial toxins (Marroquin et al. 2007; Rossignol et al. 2004). The reason for the increase in mitochondrial respiration in presence of galactose is still poorly understood. Glucose and galactose metabolism yields equivalent amounts of ATP and both 
sugars are equal as energy sources, but the shift towards respiration might be due to flux limitations through the Leloir pathway (Frey 1996; Petry et al. 1998), since galactose enters glycolysis at a lower rate than glucose (Bustamante et al. 1977). However, in presence of galactose and glutamine, HeLa cells use glutamine to provide about $98 \%$ of the ATP used for cell growth (Reitzer et al. 1979).

A non-invasive method to directly measure the metabolic response of cells to drugs and changes in substrate availability is the simultaneous measurement of heat flow and oxygen flux (Gnaiger et al. 1990). This approach not only yields baseline estimates of energy flow, but can be used to evaluate the contribution of anaerobic pathways (e.g. glycolysis) to overall cellular energy homeostasis (Guan et al. 1999; Menze et al. 2010). We found a pronounced increase in chemically uncoupled cellular respiration, but a depression in heat dissipation for cells cultured in presence of galactose compared to glucose-cultured cells, indicating a shift in metabolic poise from glycolysis to respiration.

We have investigated the effect of galactose and pioglitazone on bioenergetics and growth of HepG2 cells. Our results demonstrate that (1) galactose treatment shifts metabolic poise from glycolysis to oxidative phosphorylation, (2) pioglitazone treatment inhibits oxidative phosphorylation, (3) in presence of high glucose concentrations cells compensate for pioglitazone induced reductions in respiration via an increase in glycolysis and (4) a significant reduction in cell proliferation after addition of pioglitazone is observed in the presence of glucose, but absent if cells are dependent on galactose as a carbon source. Furthermore, increased metabolic activity induced by pioglitazone is abolished in galactose based medium. This study demonstrates that measuring cellular proliferation as an indicator of drug efficacy in the galactose-utilization model 
of cell culture can be misleading if a more detailed technique, such as calorespirometry, is not being performed. 


\section{Materials and methods}

All chemicals used for respirometry and solution preparations were of the highest grade and purchased from Sigma-Aldrich (St. Louis, MO), or Fisher Scientific (Fair Lawn, NJ). Human hepatocellular carcinoma cells (HepG2) were cultured in glucose free DMEM (Dulbecco's Modified Eagle Medium) supplemented with either $10 \mathrm{mM}$ D-galactose or glucose following the protocol described in Stokich et al. 2014. Microcalorimetry was performed following the procedures detailed in Menze et al. 2010, and respirometry measurements were based on the methods described in Stokich et al. 2014. For detailed descriptions of the employed methods please refer to the supplemental files. 


\section{RESULTS}

\section{Impact of Pioglitazone on Respiration of HepG2 Cells}

Significant reductions in oxygen flux by about $13 \%$ were observed after addition of $60 \mu \mathrm{M}$ pioglitazone to cells respiring in cell culture medium containing $10 \mathrm{mM}$ glucose $(n=6, \mathrm{p} \leq 0.05$; Fig. 1A). A more pronounced inhibitory effect of pioglitazone on cellular respiration was observed if oxygen flux was stimulated via addition of FCCP, and routine respiration rates in control cells increased nearly 3-fold in presence of this potent chemical uncoupler. After the addition of pioglitazone, the uncoupled respiration rate was significantly inhibited by about $30 \%(n=6, \mathrm{p} \leq$ 0.05; Fig 1A). Moreover, pioglitazone acted as weak chemical uncoupler in intact cells, and proton leak respiration rates in the presence of the $\mathrm{F}_{0} \mathrm{~F}_{1}$-ATPase inhibitor oligomycin $\left(\mathrm{LEAK}_{\mathrm{o}}\right.$ ) were significantly increased when pioglitazone was present $(n=6, \mathrm{p} \leq 0.05$; Fig $1 \mathrm{~A})$. This significant mitochondrial uncoupling effect of pioglitazone was a common finding throughout this study, but we did not observe statistically significant increases in oxygen consumption rates of HepG2 cultured in galactose for two weeks compared to glucose controls $(n=6, \mathrm{p}>0.05$; Fig 1B). However, maximal uncoupled respiration (FCCP) was significant higher for cells cultured in galactose and the addition of pioglitazone did not reduce uncoupled respiration rates as observed for cells cultured in glucose. Furthermore, no increase in $\mathrm{LEAK}_{\mathrm{o}}$ respiration was observed in presence of pioglitazone ( $n=6$, Fig 1B).

In order to elucidate the action(s) of pioglitazone on the oxidative phosphorylation system (OXPHOS) in more detail, HepG2 cells were permeabilized with digitonin and saturating levels of substrates were added to the sucrose based respiration medium. Two different titration protocols, promoting electron entry into the electron transport chain (ETS) via $\mathrm{FADH}_{2}$, or NADH and $\mathrm{FADH}_{2}$, were employed. In the first titration protocol, oxygen flux fueled by succinate 
dehydrogenase (complex II) activity was measured in presence of the NADH:ubiquinone oxidoreductase (complex I) inhibitor rotenone and saturating levels of succinate. When using succinate as complex II substrate the addition of pioglitazone to permeabilized cells significantly stimulated oxygen flux compared to untreated control ( $n=6, \mathrm{p} \leq 0.05$; Fig 2A, B). For cells cultured in glucose medium, respiration rates after the addition of ADP did not differ between pioglitazone treated and control cells, demonstrating that pioglitazone does not cause significant reductions in the activities of succinate dehydrogenase or the mitochondrial phosphorylation system (Fig. 2A). As with intact cells a significant uncoupling effect of pioglitazone was observed after the addition of oligomycin (Fig. 2A, B). Interestingly, pioglitazone reduced OXPHOS rates in cells cultured in galactose medium (Fig. 2B).

We next investigated the effect of pioglitazone on complex I activity followed by the concurrent presence of $\mathrm{NADH}$ and $\mathrm{FADH}_{2}$ generating substrates (Fig. 3A, B). A combination of malate, glutamate, and pyruvate was added to permeabilized cells to stimulate NADH production by mitochondrial dehydrogenases. In contrast to our results with succinate, no increase in oxygen flux was observed in presence of pioglitazone compared to untreated controls indicating an inhibition of NADH-poised respiration below an activity needed to establish a proton motive force $(\Delta \mathrm{p})$ large enough to observe the uncoupling effect of pioglitazone (Fig. 3A). The same effect was observed for cells grown in galactose based medium (Fig. 3B). A severe inhibition in complex I activity was confirmed after addition of ADP. In presence of pioglitazone, ADP failed to stimulate oxygen flux, but similar to our results with succinate alone, respiration could be rescued by the addition of succinate. $\mathrm{LEAK}_{\mathrm{o}}$ respiration after addition of oligomycin was elevated by $63 \%$ in cells treated with pioglitazone if succinate was present and slightly higher in cells grown in galactose based medium ( $n=6, \mathrm{p} \leq 0.05$; Fig 3A, B). 


\section{Pioglitazone increased heat dissipation in presence of glucose but not galactose.}

Although the exact mechanism is unknown, some immortalized cells will shift energy production from glycolysis towards mitochondrial respiration in medium supplemented with galactose instead of glucose. In contrast to respirometry, calorimetry captures the overall metabolic activity including changes in glycolytic activity. HepG2 cells cultured in glucose medium or galactose medium were treated with $60 \mu \mathrm{M}$ pioglitazone and heat dissipation was monitored every $30 \mathrm{~min}$ for $2 \mathrm{~h}$. During this period, heat dissipation dropped for galactose cultured cells, but not for cells measured in glucose medium (Table 1). However, after $30 \mathrm{~min}$ of exposure to pioglitazone, heat dissipation of HepG2 cells in glucose-containing medium was increased by about $15 \%$, but no increase was observed for galactose-treated cells. Furthermore, overall heat output was about $17 \%$ lower for cells cultured in presence of galactose compared to cells in glucose medium (Table 1). Heat dissipation data demonstrated an overall reduction in metabolic activity and indicated that cells cultured in galactose-based medium might be characterized by an overall decrease in cellular proliferation. This was confirmed by following cellular growth, and the foldincrease in cells per $24 \mathrm{~h}$ period decreased by about $40 \%$ if cells were grown in galactose based medium compared to glucose. A significant drop in proliferation rate was also observed after the addition of pioglitazone to cells grown in glucose-based medium. However, no additional decrease in proliferation was observed after the addition of pioglitazone to cells grown in galactose-based medium (Table 2). 


\section{Discussion}

We have investigated the consequences of shifting metabolic poise of HepG2 cells from glycolysis to oxidative phosphorylation on pioglitazone-induced changes in metabolic activity. An increase in mitochondrial capacity was achieved by substituting glucose for galactose in the cell culture medium for two weeks. We found that pioglitazone reduced cellular respiration and increased glycolytic flux in cells cultured in presence of glucose, but not in cells cultured in galactose-based medium. Furthermore, pioglitazone severely inhibited complex I respiration in permeabilized cells, but the overall capacity for oxidative phosphorylation could be largely rescued by $\mathrm{FADH}_{2}$ production in presence of succinate. This capacity for compensation by complex II might be the reason for a less pronounced toxicity as might be expected based on the severely inhibition of complex I activity.

Pioglitazone has been well known to alter mitochondrial bioenergetics. Acute effects of pioglitazone on primary hepatocytes and isolated mitochondria showed reductions in cellular and complex I fueled respiration rates (Brunmair et al. 2004; Sanz et al. 2011). Enzymatic assays on isolated mitochondrial complexes from mouse liver demonstrated decreases in complex I and III activity with increasing pioglitazone concentrations, and the drug was shown to disassemble complex I into 4 distinct subcomplexes (Garcia-Ruiz et al. 2013). We were interested in the effect of pioglitazone on highly proliferating HepG2 cells under in vivo conditions, since the relatively low toxicity of pioglitazone seemed difficult to explain based on the pronounced inhibition of complex I. We were especially interested to determine the effects of using the galactose model of cell culture on cellular energy flow in the presence of the known mitochondrial toxin pioglitazone. In absence of anaerobic pathways, the ratio of heat flux to oxygen flux (CR-ratio) will be in the range of the theoretical oxycaloric equivalent ( -430 to $\left.-480 \mathrm{~kJ} \mathrm{~mol} \mathrm{O}_{2}\right)($ Gnaiger et al. 1990). The 10 
CR-ratio for HepG2 cells grown in glucose medium was elevated to $-520 \mathrm{~kJ} / \mathrm{mol} \mathrm{O}_{2}$ indicating anaerobic contributions to energy production. In response to $60 \mu \mathrm{M}$ pioglitazone, an increase in the CR-ratio to $-720 \mathrm{~kJ} / \mathrm{mol} \mathrm{O}_{2}$ was observed, demonstrating an increase in glycolytic activity. Reductions in mitochondrial energy production due to inhibition of respiration by pioglitazone are apparently being counteracted by an increase in glycolytic flux. This increase in glycolytic flux was absence for cells cultured in galactose-based medium. In presence of galactose cells were less glycolytic poised with a CR-ration of $-470 \mathrm{~kJ} / \mathrm{mol} \mathrm{O}_{2}$ and no increase in the CR-ratio was observed in response to pioglitazone.

While galactose treatment of immortalized cells increases oxidative capacity of mitochondria, (Marroquin et al. 2007) and indeed rescues cells partially from the Warburg effect, sensitization to mitochondrial toxins may be obscured. We did not observe reduction in proliferation rates after pioglitazone addition to cells cultured in galactose. Only by combining proliferation studies with respirometry and calorimetry were we able to gain a further insight into the mechanism of action of pioglitazone. Therefore, caution is warranted in the interpretation of toxicity and efficacy studies of drug molecules in galactose-based culture studies in the absence of thorough metabolic characterization of the treated cells. 


\section{Acknowledgments}

This work was funded by NSF grant $C H E-160944$ to M.A.M, M.K., and N.C. Furthermore, part of this work was supported by a grant from the Mindlin Foundation (MF16-US04) to M.A.M. and M.K.

\section{Author contributions}

M.A.M., M.K., and N.C. formulated the research goals and aims. M.A.M, M.K., and D.G. designed the experiments. D.G., L.A., and L.W., performed the experiments. D.G. and S.P. performed the statistical analysis of data. D.G., S.P., M.K., and M.A.M wrote the manuscript.

\section{Conflict of Interest}

The authors declare that they have no conflict of interest.

\section{Ethics statement}

This article does not contain any studies with human participants or animals performed by any of the authors. 


\section{Figure legends}

Figure 1: Respiration rates of HepG2 cells cultured in glucose (A), or galactose (B) based medium for two weeks prior to respirometry. Oxygen flux is shown for control cells (black bars), and in presence of $60 \mu \mathrm{M}$ pioglitazone (grey bars). Uncoupled respiration was induced by titrations with FCCP (FCCP), and leak respiration was recorded after inhibition of the $\mathrm{F}_{0} \mathrm{~F}_{1}$-ATPase with oligomycin (Olig). *Indicates statistically significant differences after addition of pioglitazone. \#Indicates statistically significant differences between cells cultured in glucose or galactose based medium $(n=6, \pm \mathrm{SE})$.

Figure 2: Respiration rates of HepG2 cells cultured in glucose (A), or galactose (B) based medium for two weeks prior to respirometry. Oxygen flux is shown for control cells (black bars), and in presence of $60 \mu \mathrm{M}$ pioglitazone (grey bars). Respiration rates of cells permeabilized with digitonin (Dig) were recorded in presence of the Complex I inhibitor rotenone (Rot) and the substrate succinate (Succ). OXPHOS rates were measured after the addition of ADP (ADP), and leak respiration was recorded after inhibition of the $\mathrm{F}_{0} \mathrm{~F}_{1}$-ATPase with oligomycin (Olig). *Indicate statistically significant differences after addition of pioglitazone $(n=6, \pm \mathrm{SE})$.

Figure 3: Respiration rates of HepG2 cells cultured in glucose (A) or galactose (B) based medium for two weeks prior to respirometry. Oxygen flux is shown for control cells (black bars), and in presence of $60 \mu \mathrm{M}$ pioglitazone (grey bars). Respiration rates of cells permeabilized with digitonin (Dig) were recorded in presence NADH generating substrates (MGP) and OXPHOS rates were measured after the addition of ADP (ADP). Convergent electron entry into the ubiquinone pool was initiated by addition of succinate (Succ) and leak respiration was recorded after inhibition of 13 
the $\mathrm{F}_{0} \mathrm{~F}_{1}$-ATPase with oligomycin (Olig). ${ }^{*}$ Indicate statistically significant differences after addition of pioglitazone. "Indicate statistically significant differences between cells cultured in glucose or galactose containing medium $(n=6, \pm \mathrm{SE})$. 
Table 1: Impact of galactose and pioglitazone treatment on heat dissipation of HepG2 cells.

\begin{tabular}{lllll}
\hline Condition $^{1}$ & $30 \mathrm{~min}$ & $60 \mathrm{~min}$ & $90 \mathrm{~min}$ & $120 \mathrm{~min}$ \\
\hline Glu (Vc) & $-22.49 \pm 1.27$ & $-22.97 \pm 0.90$ & $-22.46 \pm 0.90$ & $-22.24 \pm 1.09$ \\
Glu (Pio) & $-25.48^{*} \pm 0.99$ & $-25.28^{*} \pm 1.10$ & $-24.75^{*} \pm 0.97$ & $-24.19^{*} \pm 0.87$ \\
Gal (Vc) & $-18.88 \pm 1.00$ & $-15.21 \pm 0.62$ & $-13.45 \pm 0.59$ & $-11.99 \pm 0.64$ \\
Gal (Pio) & $-18.64^{\$} \pm 0.99$ & $-16.27^{\$} \pm 0.72$ & $-14.91^{\$} \pm 0.60$ & $-13.79^{\$} \pm 0.52$ \\
\hline
\end{tabular}

${ }^{1}$ Cells were cultured and evaluated in galactose (Gal) or glucose (Glu) based medium, and response to $60 \mu \mathrm{M}$ of pioglitazone (Pio), or DMSO (vehicle control, Vc) was recorded. The cells were cultured for a minimum of two weeks in presence of the respective sugar prior to calorimetry. ${ }^{1}$ all data are shown in $\mu \mathrm{W}$. *statistically significant increase in heat dissipation after addition of pioglitazone. ${ }^{\$}$ statistically significant decrease in heat dissipation compared to glucose plus pioglitazone $(n=5-8, \pm \mathrm{SE}, \mathrm{P}<0.05)$.

Table 2: Impact of galactose and pioglitazone treatment on proliferation rates of HepG2 cells.

\begin{tabular}{ll}
\hline Condition $^{1}$ & Fold-increase in cells \\
\hline Glu (Vc) & $2.19 \pm 0.15$ \\
Glu (Pio) & $1.77^{*} \pm 0.02$ \\
Gal (Vc) & $1.37^{\$} \pm 0.05$ \\
Gal (Pio) & $1.17^{\$} \pm 0.15$ \\
\hline
\end{tabular}

${ }^{1}$ Cells were cultured for two weeks in presence of galactose (Gal) or glucose (Glu) prior to the proliferation assays. Cells were plated in absence of drugs and $60 \mu \mathrm{M}$ of pioglitazone (Pio), or DMSO (vehicle control, Vc) was added after $24 \mathrm{~h}$. Cells were enumerated after an additional $24 \mathrm{~h}$ of incubation. *statistically significant decrease in cell proliferation after addition of pioglitazone.

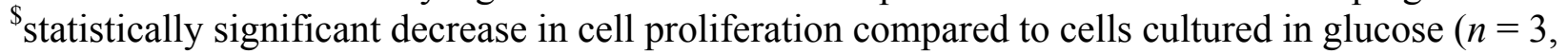
\pm SE $\mathrm{P}<0.05)$. 
Figures:

Fig. 1

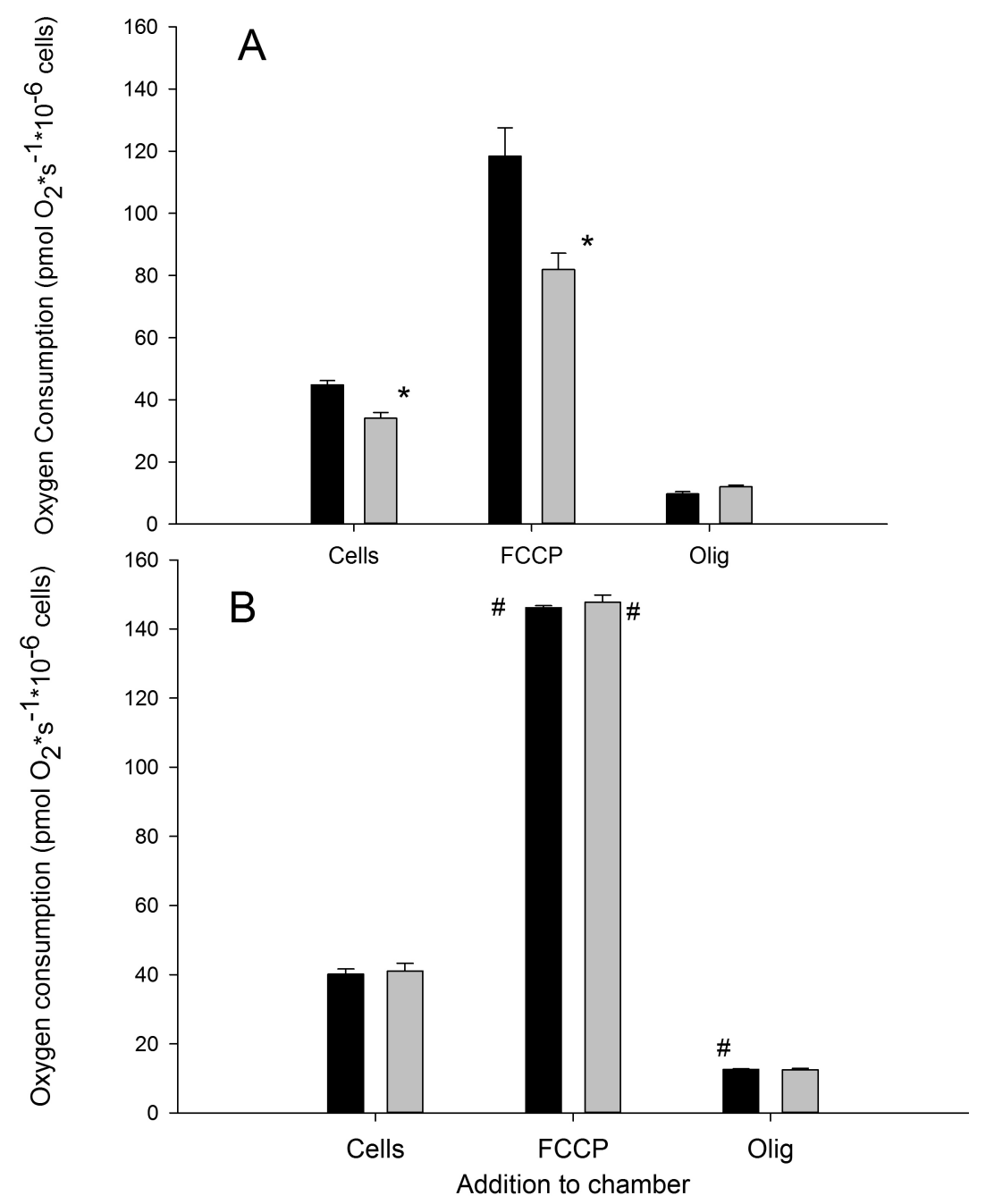


Fig. 2
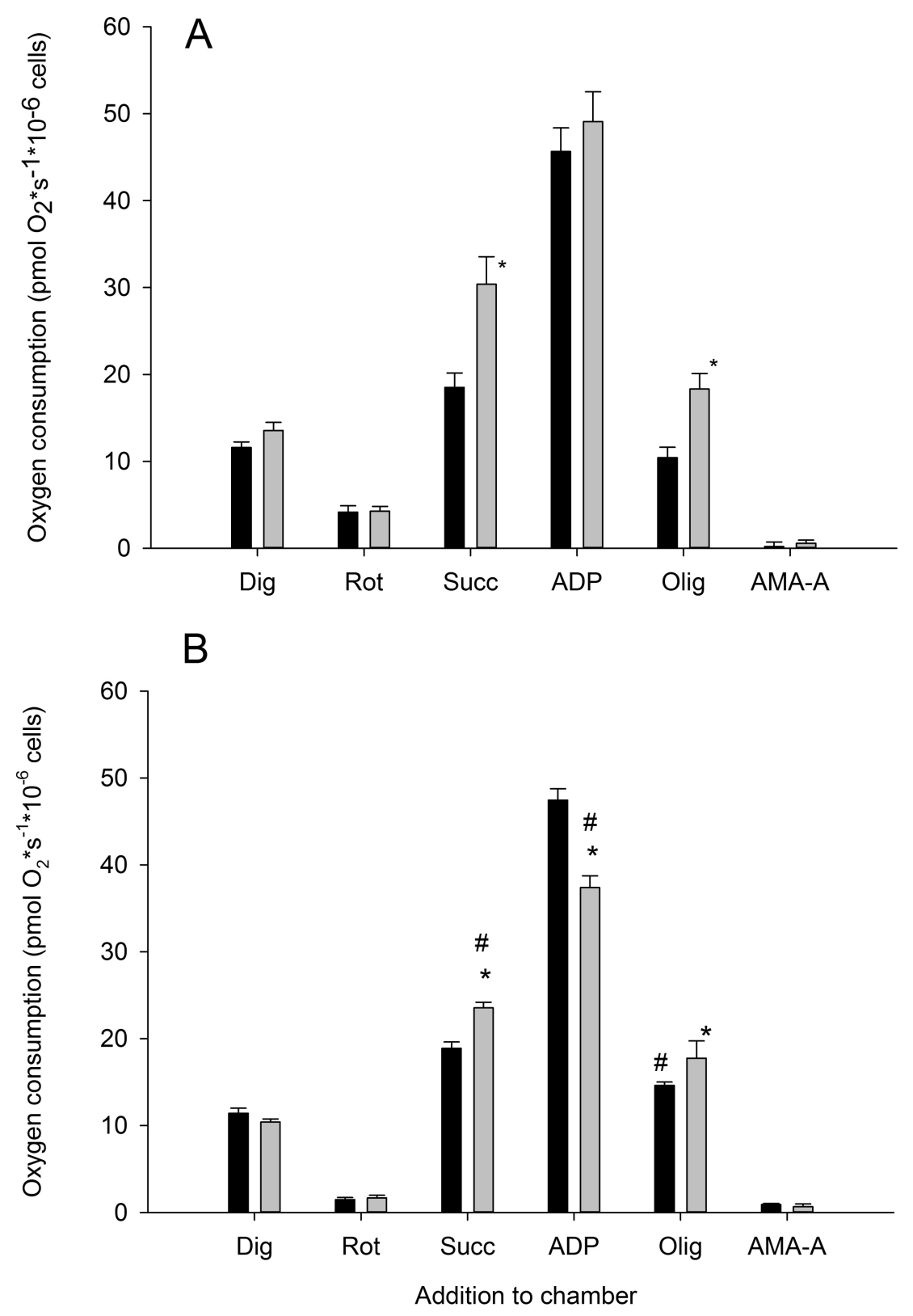
Fig. 3
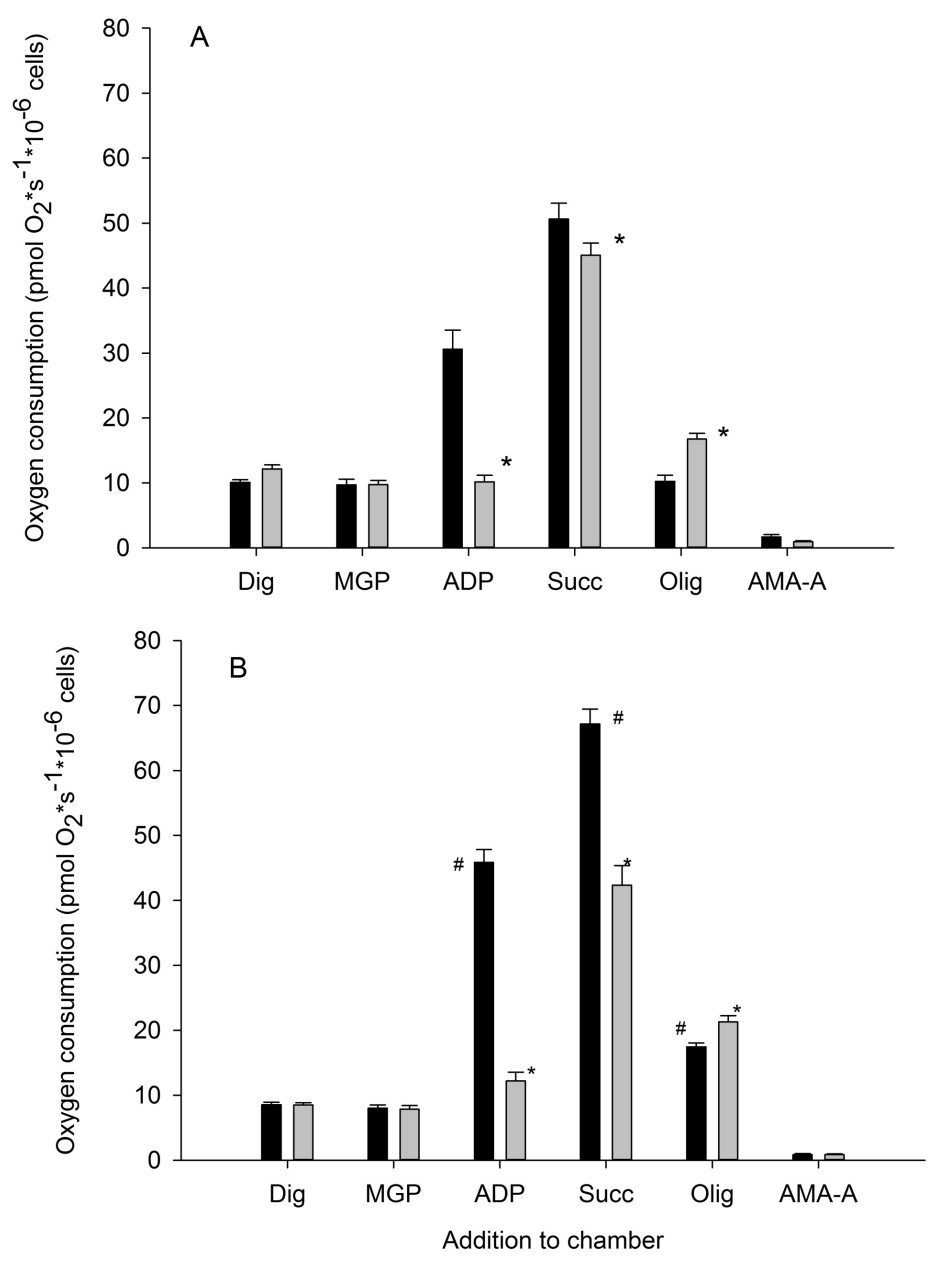


\section{References}

Brunmair B, Staniek K, Gras F, Scharf N, Althaym A, Clara R, Roden M, Gnaiger E, Nohl H, Waldhausl W, Furnsinn C (2004) Thiazolidinediones, like metformin, inhibit respiratory complex I: a common mechanism contributing to their antidiabetic actions? Diabetes 53:1052-1059

Bustamante E, Pedersen PL (1977) High aerobic glycolysis of rat hepatoma cells in culture: role of mitochondrial hexokinase. P Natl Acad Sci USA 74:3735-3739

Cariou B, Charbonnel B, Staels B (2012) Thiazolidinediones and PPARgamma agonists: time for a reassessment. Trends Endocrin Met: 23:205-215

Colca JR, McDonald WG, Waldon DJ, Leone JW, Lull JM, Bannow CA, Lund ET, Mathews WR (2004) Identification of a novel mitochondrial protein ("mitoNEET") cross-linked specifically by a thiazolidinedione photoprobe. Am J Physiol Endoc M 286:E252-260

Day C (1999) Thiazolidinediones: a new class of antidiabetic drugs. Diabetic Med 16:179-192

DeFronzo RA, Tripathy D, Schwenke DC, Banerji M, Bray GA, Buchanan TA, Clement SC, Henry RR, Hodis HN, Kitabchi AE, Mack WJ, Mudaliar S, Ratner RE, Williams K, Stentz FB, Musi N, Reaven PD, Study AN (2011) Pioglitazone for diabetes prevention in impaired glucose tolerance. New Engl J Med 364:1104-1115

Diaz-Ruiz R, Rigoulet M, Devin A (2011) The Warburg and Crabtree effects: On the origin of cancer cell energy metabolism and of yeast glucose repression. BBA - Bioenergetics 1807:568-576

Divakaruni AS, Wiley SE, Rogers GW, Andreyev AY, Petrosyan S, Loviscach M, Wall EA, Yadava N, Heuck AP, Ferrick DA, Henry RR, McDonald WG, Colca JR, Simon MI, Ciaraldi TP, Murphy AN (2013) Thiazolidinediones are acute, specific inhibitors of the mitochondrial pyruvate carrier. P Natl Acad Sci USA 110:5422-5427

Feinstein DL, Spagnolo A, Akar C, Weinberg G, Murphy P, Gavrilyuk V, Dello Russo C (2005) Receptor-independent actions of PPAR thiazolidinedione agonists: is mitochondrial function the key? Biochem Pharmacol 70:177-188

Frey PA (1996) The Leloir pathway: a mechanistic imperative for three enzymes to change the stereochemical configuration of a single carbon in galactose. FASEB J 10:461-470

Garcia-Ruiz I, Solis-Munoz P, Fernandez-Moreira D, Munoz-Yague T, Solis-Herruzo JA (2013) Pioglitazone leads to an inactivation and disassembly of complex I of the mitochondrial respiratory chain. BMC Biol 11:88

Geldenhuys WJ, Leeper TC, Carroll RT (2014) mitoNEET as a novel drug target for mitochondrial dysfunction. Drug Discov Today 19:1601-1606

Gnaiger E, Kemp RB (1990) Anaerobic metabolism in aerobic mammalian cells: information from the ratio of calorimetric heat flux and respirometric oxygen flux. Biochim Biophys Acta 1016:328-332

Guan YH, Kemp RB (1999) Detection of the changing substrate requirements of cultured animal cells by stoichiometric growth equations validated by enthalpy balances. J Biotechnol 69:95-114 
Ibsen KH (1961) The Crabtree effect: a review. Cancer Res 21:829-841

Kim JW, Dang CV (2006) Cancer's molecular sweet tooth and the Warburg effect. Cancer Res 66:8927-8930

Marroquin LD, Hynes J, Dykens JA, Jamieson JD, Will Y (2007) Circumventing the Crabtree effect: replacing media glucose with galactose increases susceptibility of HepG2 cells to mitochondrial toxicants. Toxicol Sci: 97:539-547

Menze MA, Chakraborty N, Clavenna M, Banerjee M, Liu XH, Toner M, Hand SC (2010) Metabolic preconditioning of cells with AICAR-riboside: improved cryopreservation and cell-type specific impacts on energetics and proliferation. Cryobiology 61:79-88

Paddock ML, Wiley SE, Axelrod HL, Cohen AE, Roy M, Abresch EC, Capraro D, Murphy AN, Nechushtai R, Dixon JE, Jennings PA (2007) MitoNEET is a uniquely folded 2Fe 2S outer mitochondrial membrane protein stabilized by pioglitazone. P Natl Acad Sci USA 104:14342-14347

Petry KG, Reichardt JK (1998) The fundamental importance of human galactose metabolism: lessons from genetics and biochemistry. Trends Genet 14:98-102

Reitzer LJ, Wice BM, Kennell D (1979) Evidence that glutamine, not sugar, is the major energy source for cultured HeLa cells. J Biol Chem 254:2669-2676

Rossignol R, Gilkerson R, Aggeler R, Yamagata K, Remington SJ, Capaldi RA (2004) Energy substrate modulates mitochondrial structure and oxidative capacity in cancer cells. Cancer Res 64:985-993

Sanz MN, Sanchez-Martin C, Detaille D, Vial G, Rigoulet M, El-Mir MY, Rodriguez-Villanueva $\mathrm{G}$ (2011) Acute mitochondrial actions of glitazones on the liver: a crucial parameter for their antidiabetic properties. Cell Physiol Biochem 28:899-910

Stokich B, Osgood Q, Grimm D, Moorthy S, Chakraborty N, Menze MA (2014) Cryopreservation of hepatocyte (HepG2) cell monolayers: impact of trehalose. Cryobiology 69:281-290

Vander Heiden MG, Cantley LC, Thompson CB (2009) Understanding the Warburg effect: the metabolic requirements of cell proliferation. Science 324:1029-1033

Warburg O (1956) On the origin of cancer cells. Science 123:309-314 


\section{Supplemental Files - Material and Methods}

\section{Chemicals}

All chemicals used for respirometry and solution preparations were of the highest grade and purchased from Sigma-Aldrich (St. Louis, MO), or Fisher Scientific (Fair Lawn, NJ). Water for solution preparation was purified with a Milli-Q Reagent Water System (Billerica, MA) to an electrical resistance of $18 \mathrm{~m} \Omega$.

\section{Cell culture}

Human hepatocellular carcinoma cells $(\mathrm{HepG} 2)$ were obtained from the American Type Culture Collection (ATCC, Manassas, VA) and grown in $75 \mathrm{~cm}^{2}$ cell culture flasks (Corning Incorporated, Corning, NY). Standard cell culture medium to maintain HepG2 cells was composed of Opti-MEM I reduced serum medium (ThermoFisher, Grand Island, NY) supplemented with 5.5\% fetal bovine serum (FBS) (Atlanta Biologicals Inc., Flowery Branch, GA), 100 units/ml penicillin, $100 \mu \mathrm{g} / \mathrm{ml}$ streptomycin, and $250 \mathrm{ng} / \mathrm{ml}$ amphotericin B (MP Biomedicals, Santa Anna, CA). Galactose treatment groups were cultured for a minimum of four weeks in glucose free DMEM (Dulbecco's Modified Eagle Medium) supplemented with $10 \mathrm{mM}$ D-galactose, $2 \mathrm{mM}$ glutamine, $1 \mathrm{mM}$ pyruvate (all from ThermoFisher, Grand Island, NY), plus $10 \%$ dialyzed or complete FBS as indicated in the figure legends (Gal-DMEM). Gal-DMEM medium prepared with complete FBS contained $>0.2 \mathrm{mM}$ glucose (data not shown). For experiments directly comparing the impact of high glucose and galactose, cells were cultured in the above medium supplemented with $10 \mathrm{mM}$ glucose instead of galactose (Glu-DMEM). The cells were maintained in a humidified atmosphere of $6.5 \% \mathrm{CO}_{2}$ and $93.5 \%$ air at $37{ }^{\circ} \mathrm{C}$ and the culture medium was renewed every $3-4$ days. The cells were subcultured every seven days or before reaching $90 \%$ confluency. To 
subculture, cells were dissociated using $0.25 \%$ trypsin and $1 \mathrm{mM}$ EDTA in balanced salt solution (ThermoFisher, Grand Island, NY) and reseeded at $1.5 \cdot 10^{6}$ cells per $75 \mathrm{~cm}^{2}$ cell culture flasks.

\section{Microcalorimetry}

Heat dissipation of HepG2 cells was measured as described before (Menzeet al. 2010). Briefly, the LKB 2277 thermal activity monitor (Bromma, Sweden) was charged with a $4 \mathrm{~mL}$ sealed ampoule filled with $2.5 \mathrm{~mL}$ of HepG2 cells in suspension to measure heat dissipation. Cells were diluted in culture medium equilibrated with $10 \% \mathrm{CO}_{2}$ and $90 \%$ air to yield 500,000 cells per $2.5 \mathrm{~mL}$ of medium. The medium formulations (Gal-DMEM and Glu-DMEM) used to measure cellular heat dissipation were identical to the ones used for cell culture. The reference vessel contained $2.5 \mathrm{~mL}$ of water and all calorimetric measurements were performed at $37^{\circ} \mathrm{C}$. A $15 \mathrm{~min}$ period for thermal equilibration was allowed after the ampoule was lowered into the calorimeter, and the heat flow $(\mu \mathrm{W})$ was recorded for $2 \mathrm{~h}$. Pioglitazone stock solutions $(6 \mathrm{mM})$ were prepared in dimethyl sulfoxide (DMSO). Heat dissipation of cells without pioglitazone was measured in presence of DMSO alone (vehicle control) and treated cells were exposed to a final concentration of $60 \mu \mathrm{M}$ pioglitazone.

\section{Respirometry on HepG2 cells}

Respiration was measured at $37^{\circ} \mathrm{C}$ using $1 \times 10^{6}$ cells per $\mathrm{mL}$ in each chamber of the Oxygraph-2K (OROBOROS Instruments, Innsbruck, Austria). Routine respiration of intact cells was measured in either Opti-MEM I reduced serum medium, DMEM supplemented with glucose, or DMEM supplemented with galactose. The media formulations in these experiments were identical to the media used to culture cells. In some experiments, cellular respiration was uncoupled by successive titrations of carbonyl cyanide 4-(trifluoromethoxy) phenylhydrazone (FCCP; $0.5 \mu \mathrm{M}$ steps), and leak respiration was measured in the presence of oligomycin $(2 \mu \mathrm{g} / \mathrm{mL})$. 
Oxygen consumption of permeabilized cells was measured in $2 \mathrm{~mL}$ of MiR05 (110 mM sucrose, $60 \mathrm{mM}$ potassium lactobionate, $20 \mathrm{mM}$ taurine, $10 \mathrm{mM} \mathrm{KH}_{2} \mathrm{PO}_{4}, 3 \mathrm{mM} \mathrm{MgCl} 2,0.5 \mathrm{mM}$ EGTA, 0.1\% BSA, $20 \mathrm{mM}$ HEPES-KOH, $\mathrm{pH}$ 7.1). In order to supply mitochondrial substrates, cells were permeabilized by the addition of digitonin dissolved in dimethyl sulfoxide (DMSO) at $10 \mathrm{mg} / \mathrm{mL}$ (final concentration $10 \mu \mathrm{g} \times 10^{-6}$ cells). This digitonin concentration was found to be sufficient to permeabilize the plasma membrane of HepG2 cells with minimal impact on the integrity of the outer mitochondrial membrane as tested by addition of cytochrome $c$. Electron flow through complex I was stimulated by adding $2 \mathrm{mM}$ malate, $10 \mathrm{mM}$ glutamate, and $5 \mathrm{mM}$ pyruvate. To engage the phosphorylation system, $1 \mathrm{mM}$ ADP was added followed by the addition of $10 \mathrm{mM}$ succinate to supply electrons to the ubiquinone pool via succinate dehydrogenase. Leak respiration in presence of ADP and ATP was measured after addition of oligomycin $(2 \mu \mathrm{g} / \mathrm{mL})$, and contribution of complex I to leak respiration was recorded after addition of rotenone $(0.5 \mu \mathrm{M})$. Non-mitochondrial oxygen consumption was recorded after addition of $2.5 \mu \mathrm{M}$ of antimycin A. DATLAB software (OROBOROS Instruments, Innsbruck, Austria) was used for data analysis and acquisition.

\section{Impact of pioglitazone on cell proliferation}

Approximately 500,000 cells were plated per well on 12-well plates, placed in a humidified atmosphere of $6.5 \% \mathrm{CO}_{2}$ and $93.5 \%$ air at $37{ }^{\circ} \mathrm{C}$, and grown in glucose or galactose containing medium. After $24 \mathrm{~h}$ cell counts were performed on untreated control cells. Samples for proliferation assays were exposed to pioglitazone concentrations of 0 or $60 \mu \mathrm{M}$ and after an additional $24 \mathrm{~h}$ of culture time, treated and untreated cells were enumerated using a hemocytometer. Membrane integrity was assessed by diluting samples in a 1:1 ratio with trypan blue prior to cell counts and only trypan blue negative cells were used to calculate cellular 23 
proliferation rates. Fold increase in cell numbers were expressed as numbers of cells recovered after $24 \mathrm{~h}$ of plating divided by cell numbers recovered after $48 \mathrm{~h}$.

\section{Statistical analyses}

Data were analyzed with a one-way analysis of variance (ANOVA) on ranks followed by comparison of experimental groups with the appropriate control group (Holm-Sidak method), or 2-way ANOVA followed by comparison of experimental groups with the appropriate control groups (Holm-Sidak method). SigmaPlot 12.5 (Systat Software Inc., San Jose, CA) was used for the analyses. 